\title{
UMA REFLEXÃO SOBRE GESTÃO DO CONHECIMENTO X VIRTUA: TENDÊNCIA DO SISTEMA DE BIBLIOTECAS DA UNICAMP (SBU)
}

\section{Ademir Giacomo Pietrosanto}

Resumo: Este artigo faz uma reflexão sobre os aspectos práticos da gestão do conhecimento aplicados ao módulo de circulação do software de funções integradas Virtua/VTLS, implantado e utilizados pelas bibliotecas do Sistema de Bibliotecas da UNICAMP, fazendo uma comparação e análise através de revisão de literatura em relação as atitudes e comportamentos dos bibliotecários, usuários deste novo sistema de empréstimo, visando a forma e operacionalização dos bibliotecários com as novas tecnologias.

Palavras-chave: Sistema de empréstimo automatizado; Gestão do conhecimento; Bibliotecários.

Abstract: This article makes a reflection on the practical aspects of the management of the knowledge applied to the module of circulation of the software of integrated functions Virtua/VTLS, implanted and used for libraries of the System of Libraries of the UNICAMP, making a comparison and analysis through revision of literature in relation the attitudes and behaviors of the librarians, users of this new system of loan, aiming at the form of work of the librarians with the new technologies.

Keywords: System of automatized loan; Management of the knowledge; Librarians. 


\section{ARTIGO \\ Biblioteconomia \& Ciência da Informação}

\section{INTRODUÇÃO}

Com o conhecimento se nasce e a informação se adquire. Será isso certo em nossos pensamentos e ações? Senão, vejamos a gestão do conhecimento hoje em dia, toma conta da sociedade como um todo. Ela “é um conjunto de processos que governam a criação, o uso e disseminação do conhecimento na organização, de forma a atingir seus objetivos de negócios”.(INFORMAL INFORMÁTICA, 2003)

Rodrigues, Antunes, Dutra (2003), nos diz que estamos vivendo transformações, mas se estamos preparados em termos de gestão. Esses autores nos questionam que os processos de gestão eram inicialmente dirigidos para o homem e, com o avanço tecnológico, foi introduzida a visão de sistema de empresa.

Santos (2003), cita Bill Gates em sua obra de 1999 que, "se os anos oitenta foram o decênio da qualidade e os noventa o da reengenharia de processos, o primeiro decênio a partir de 2000 será o da velocidade”.

Portanto, o que tem a ver o software Virtua, módulo circulação com a gestão do conhecimento? Tudo seria a resposta definitiva e acertada, pois se conhecermos o software veremos que tudo está relacionado com a gestão do conhecimento.

A busca da informação já é gestão do conhecimento e engloba pessoas que estão certas para alcançá-la. (SANTOS, 2003).

Teixeira Filho (2003) comenta que, as pessoas derivam ter conhecimento das informações de diversas formas: por comparação, pela experimentação, por conexão com outros conhecimentos e através das outras pessoas.

As pessoas são competentes não só do ponto de vista cognitivo, mas também do emocional (SANTOS, 2003). 


\section{MÓDULO DE CIRCULAÇÃO DO SOFTWARE DE FUNÇOES INTEGRADAS} VIRTUA/VTLS

O software Virtua está estruturado em quatro (04) funções básicas, apresentadas da seguinte forma:

- $\quad$ Referência (OPAC)

- Catalogação

- Periódicos (Aquisições)

- Circulação

O módulo Circulação controla todas as funções rotineiras, com base nas políticas de cada biblioteca, porém o Sistema de Bibliotecas da UNICAMP (SBU) adotou uma política uniforme, ou seja , todas as bibliotecas seguirão um padrão de circulação dos materiais que serão emprestados, ou seja livros e teses, no inicio do módulo. (PIETROSANTO et al., 2001)

O módulo tem quatro (04) funções básicas: empréstimo, devolução, renovação e reserva.

\subsection{Empréstimo}

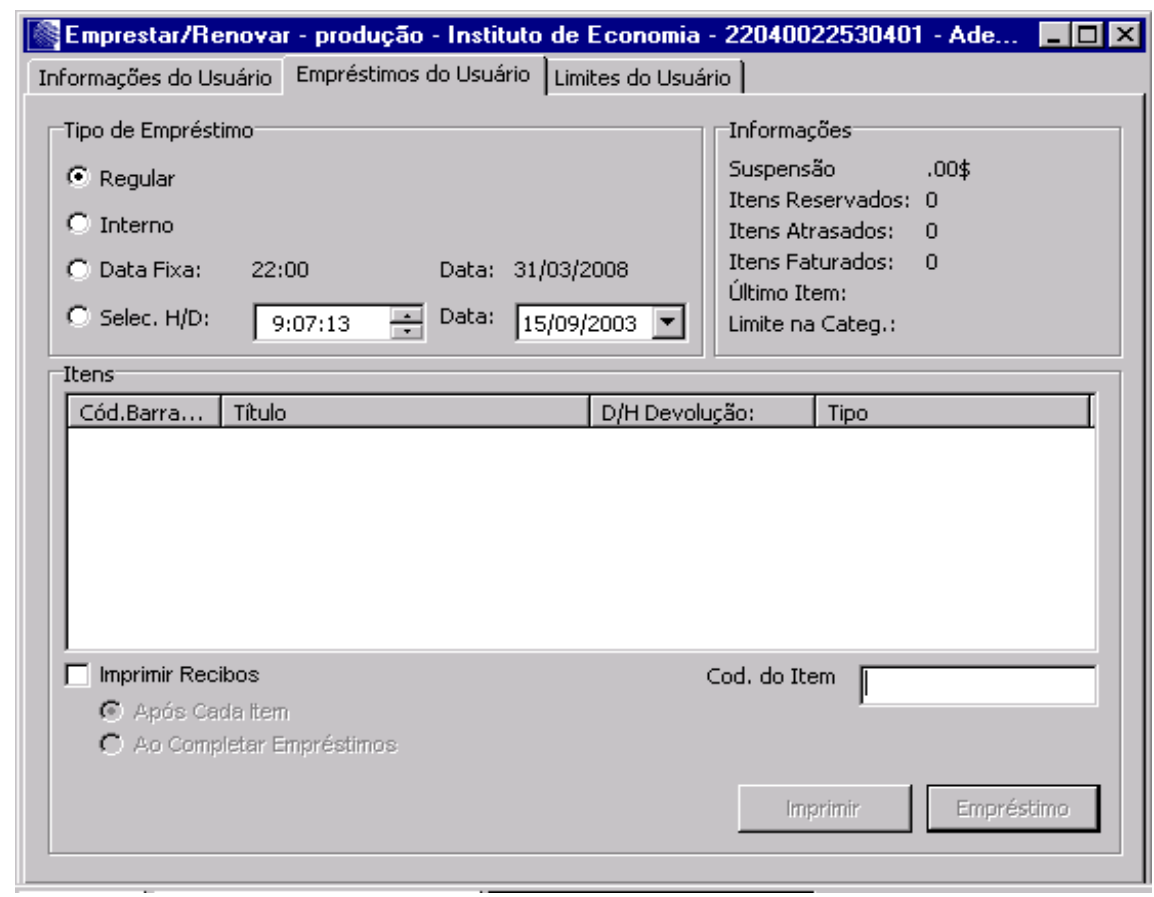

(C) ETD - Educação Temática Digital, Campinas, SP, v.6, n.1, p.1-9, dez. 2004 - ISSN: 1676-2592. 


\subsection{Devolução}

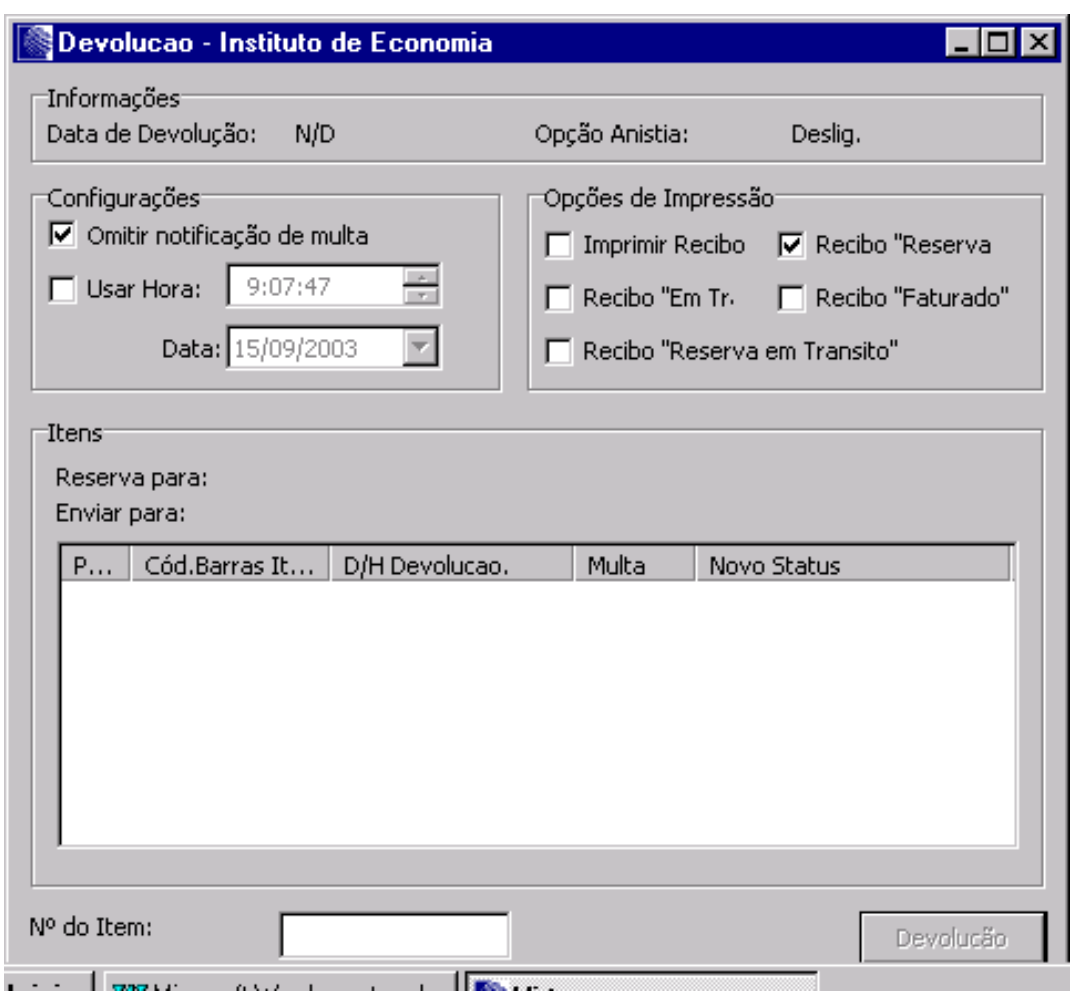

\subsection{Renovação}

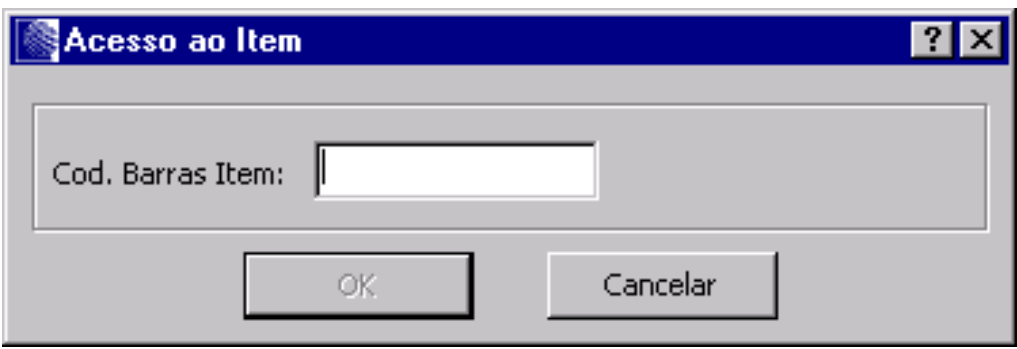

\subsection{Reserva}

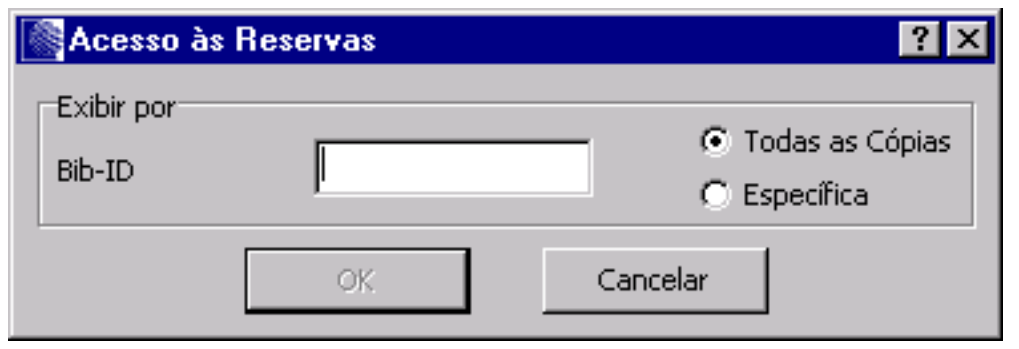

(C) ETD - Educação Temática Digital, Campinas, SP, v.6, n.1, p.1-9, dez. 2004 - ISSN: 1676-2592. 
Cada item tem sua característica: o empréstimo e devolução exigem o mínimo do operador, visto usarmos o leitor de código de barras. O item renovação também é visto como um novo empréstimo, mas caso o item estiver reservado, aparecerá uma mensagem dizendo para que o item deverá ser "guardado” na estante de reserva.

Quanto ao item reserva, requer muita atenção do operador e portando temos que recorrer muito ao manual de circulação (PIETROSANTO, 2003).

Neste item temos varias opções de reserva: pelo item, pelo título e pelo Bib-ID, o mais correto de se fazer.

Vantagens de se usar o módulo circulação Virtua:

- Interação e padronização com os outros módulos do sistema (OPAC, Catalogação e Periódicos);

- Funcionamento em rede;

- Bloqueio automático do usuário

- Permissão ao usuário para verificar o seu status junto ao modulo

- Permissão ao usuário verificar localmente sua situação com ao SBU (PIETROSANTO et al., 2001)

Um dos grandes fatores que nos privilegia a implantação definitiva deste modulo circulação, é o fato de sermos a primeira instituição a utilizar o Virtua no Brasil

\section{INTERAÇÃO : BIBLIOTECÁRIOS DO SBU X GESTÃO DO CONHECIMENTO $X$ VIRTUA}

Quando queremos dizer que a gestão do conhecimento esta interligada ao software Virtua, modulo circulação, sentimos a necessidade de se adaptar a nova realidade mundial de competitividade e qualidade que tem levado as organizações a repensar quais os fatores que efetivamente garantem a excelência na prestação dos seus serviços (LONGO; VERGUEIRO, 2003).

Os cientistas da informação, bibliotecários ou mesmos pesquisadores do Sistema de Bibliotecas da UNICAMP (SBU) ainda estão em fase dessa adaptação, sentindo, as vezes , 
medo da mudança, da nova tecnologia, das inovações tecnológicas e de se adaptar a nova cultura de trabalho. A adaptabilidade e transformação, a gestão da qualidade pode representar uma alternativa viável para que os serviços de informação ofereçam resposta apropriada às exigências de um novo tempo. (LONGO ; VERGUEIRO, 2003)

Colocando o modulo circulação em movimento nas unidades da UNICAMP este software pode oferecer que:

- As pessoas relacionam-se melhor consigo mesma e com o seu trabalho;

- Os funcionários sintam mais orgulhosos daquilo que fazem;

- Tenha relacionamento mais aberto entre as pessoas da unidade;

- Dirigentes sentindo-se menos isolados;

- Haja aumento da produtividade;

- O atendimento, cumprindo parâmetros preestabelecidos pelo sistema;

- O moral dos funcionários, clientes internos (usuários) fiquem satisfeitos com a nova tecnologia implantada;

- A segurança, tanto para os usuários externos que recebem o produto ou o serviço como para os funcionários da unidade.

Portanto, as pessoas de informação aparecem, com títulos diferentes em países diferentes, mas semelhantes na função, seja ela bibliotecário, cientista da informação ou mesmo pesquisador cientifico. E esta função dita de maneira simples é assegurar que aquelas pessoas que necessitam de conhecimento em seu trabalho... (FREIRE, 2003)

\section{CONSIDERAÇÕES FINAIS}

Pode-se dizer que a gestão do conhecimento é um aprendizado organizacional que processa a detecção e ocorrência de erros (GARVIN, 2000). O aprendizado organizacional ocorre por meio de compartilhamento de idéias, conhecimentos e modelos mentais e se fundamenta no conhecimento e experiências do passado (GARVIN, 2000).

Essas duas citações nos levam a refletir o papel do bibliotecário junto à gestão do conhecimento: ERROS, EXPERIÊNCIA DO PASSADO, COMPARTILAMENTO DE IDÉIAS, MODELOS MENTAIS. Tudo isso ocorre com todo e qualquer profissional que lida com as inovações tecnológicas, ou seja, mudança de hábito de uma teoria para outra. 
Argyris (2000) nos fala que a maioria das pessoas define o aprendizado, no nosso caso, o VIRTUA, de maneira muito estreita, com mera “solução de problemas”, e assim se concentra na identificação e correção de erros no ambiente externo. Portanto, a solução dos problemas que aparentemente surgirão é importante para o aprendizado constante dos bibliotecários e auxiliares que usarão esse módulo de circulação Virtua, mas para que o aprendizado seja duradouro, os gerentes e bibliotecários devem olhar para dentro de si mesmo.

Por isso, a gestão da coordenação do software Virtua na UNICAMP, situa-se no contexto da gestão de pessoas que é representado pelo SBU. Em resumo, o SBU é constituído de pessoas (bibliotecários), e dependem delas para atingir seus objetivos e cumprir suas missões. (CHIAVENATO, 1999).

Concluindo, Kawasaki (1999) ${ }^{1}$ citado por Rodrigues (2003, p.72) propõe dizendo que, para uma boa gestão contemporânea, as novas abordagens da gestão propõem que:

- Crie (pense diferente; não se preocupe; seja imperfeito; aprimore);

- Comande (rompa barreiras; crise seguidores; evite os imãs fatais);

- Trabalhe (coma como um passarinho; despache como um elefante; pense de forma digital; aja de forma analógica; não peça a ninguém para fazer aquilo que você não fará).

Neste contexto, é dessa forma que estamos propondo com o módulo circulação Virtua, para que todos tenham um comportamento igual e referenciado dentro da universidade, e assim valorizando mais nossos serviços juntos aos usuários do sistema.

\section{REFERÊNCIAS}

ARGYRIS, Chris. Ensinando pessoas inteligentes a aprender. In: GESTÃo do conhecimento. Tradução de: Afonso Celso de Cunha Serra. Rio de Janeiro: Campus, 2000, p. 82-107.

\footnotetext{
${ }^{1}$ KAWASAKI, G. Regras para revolucionários. Rio de Janeiro: Campus, 1999.
} 
CHIAVENATO, Idalberto. Gestão de pessoas: o novo papel dos recursos humanos nas organizações. Rio de Janeiro: Campus, 1999. 457p;

FREIRE, Isa Maria. O olhar da consciência possível sobre o campo científico. Ci. Inf., Brasília, v.32, n.1, p.50-59, jan./abr. 2003.

GARVIN, David A. Construindo a organização que aprende. In: GESTÃo do conhecimento. Tradução de: Afonso Celso da Cunha Serra. Rio de Janeiro: Campus, 2000. p.50-81.

INFORMAL INFORMÁTICA. FAQ : o que é gestão do conhecimento?. Disponível em: <http://www.informal.com.br/faq/faq001.html>. Acesso em: 30 jul. 2003.

LONGO, Rose Mary Juliano ; VERGUEIRO, Waldomiro. Gestão da qualidade em serviços de informação do setor público: características e dificuldades para sua implantação. Rev. dig. Bibliotecon. \& Ci. Inf., Campinas, v.1, n.1, p.39-59, jul./dez. 2003.

PIETROSANTO, Ademir Giacomo. Manual de circulação VIRTUA/VTLS : versão 2.0

- simplificada. Campinas: IE/UNICAMP, 2003. 40p.

et al. Implementação de um módulo de circulação, através do software de funções integradas VIRTUA/VTLS : a experiência do Sistema de Bibliotecas da UNICAMP. In: SEMINÁRIO NACIONAL DE BIBLIOTECAS UNIVERSITÁRIAS, 10., 2000, Florianópolis. Anais eletrônicos...Florianópolis : UFSC/BC, 2000.

RODRIGUES, Hugo Túlio ; ANTUNES, Adelaide Maria de Souza ; DUTRA, Luís Eduardo Duque. Análise de propostas de modelos de gestão direcionados para o conhecimento. Rev. Adm., São Paulo, v.38, n.1, p.66-76, jan./fev./mar. 2003.

SANTOS, Armando Cuesta. Gestão do conhecimento, da organização que aprende e de competências: a era digital. Rev. Adm., São Paulo, v.38, n.1, p.77-83, jan./fev./mar. 2003.

TEIXEIRA FILHO, Jayme. Capital intelectual e gestão de recursos humanos. Disponível em: <http:\\ivrokm-cd\artigos\CapInt_GRH.html>. Acesso em: 20 jul. 2003. 


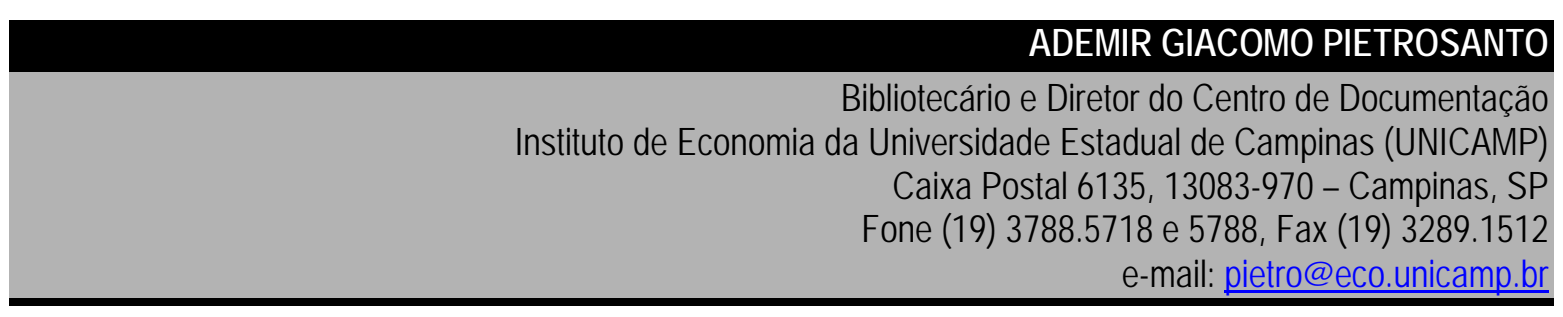

Recebido em: 10/10/2004

Aceito em: 05/01/2005 